Article

\title{
Effect of Honokiol on Cytochrome P450 and UDP-Glucuronosyltransferase Enzyme Activities in Human Liver Microsomes
}

Hyeon-Uk Jeong ${ }^{1}$, Tae Yeon Kong ${ }^{1}$, Soon Sang Kwon ${ }^{1}$, Sung-Woon Hong ${ }^{2}$, Sung Hum Yeon ${ }^{2}$, Jun-Ho Choi ${ }^{2}$, Jae Young Lee ${ }^{2}$, Yong Yeon Cho ${ }^{1}$ and Hye Suk Lee ${ }^{1, *}$

1 College of Pharmacy, the Catholic University of Korea, Bucheon 420-743, Korea;

E-Mails: wjd1375@hanmail.net (H.-U.J.); kongtaeyun@naver.com (T.Y.K.);

zuzutnseo@naver.com (S.S.K.); yongyeon@catholic.ac.kr (Y.Y.C.)

2 Huons Co., Ltd., Ansan 426-791, Korea; E-Mails: swhong@huons.com (S.-W.H.); yon3547@huons.com (S.H.Y.); cool841123@huons.com (J.-H.C.);

leonrekaivalya@huons.com (J.Y.L.)

* Author to whom correspondence should be addressed; E-Mail: sianalee@catholic.ac.kr;

Tel.: +82-2-2164-4061; Fax: +82-32-342-2013.

Received: 15 August 2013; in revised form: 28 August 2013 / Accepted: 28 August 2013 /

Published: 3 September 2013

\begin{abstract}
Honokiol is a bioactive component isolated from the medicinal herbs Magnolia officinalis and Magnolia grandiflora that has antioxidative, anti-inflammatory, antithrombotic, and antitumor activities. The inhibitory potentials of honokiol on eight major human cytochrome P450 (CYP) enzymes 1A2, 2A6, 2B6, 2C8, 2C9, 2C19, 2D6, and $3 \mathrm{~A} 4$, and four UDP-glucuronosyltransferases (UGTs) 1A1, 1A4, 1A9, and 2B7 in human liver microsomes were investigated using liquid chromatography-tandem mass spectrometry. Honokiol strongly inhibited CYP1A2-mediated phenacetin $O$-deethylation, CYP2C8-mediated amodiaquine $\mathrm{N}$-deethylation, CYP2C9-mediated diclofenac 4-hydroxylation, CYP2C19mediated [S]-mephenytoin 4-hydroxylation, and UGT1A9-mediated propofol glucuronidation with $K_{\mathrm{i}}$ values of $1.2,4.9,0.54,0.57$, and $0.3 \mu \mathrm{M}$, respectively. Honokiol also moderately inhibited CYP2B6-mediated bupropion hydroxylation and CYP2D6-mediated bufuralol 1'-hydroxylation with $K_{\mathrm{i}}$ values of 17.5 and $12.0 \mu \mathrm{M}$, respectively. These in vitro results indicate that honokiol has the potential to cause pharmacokinetic drug interactions with other co-administered drugs metabolized by CYP1A2, CYP2C8, CYP2C9, CYP2C19, and UGT1A9.
\end{abstract}


Keywords: honokiol; cytochrome P450 inhibition; UDP-glucuronosyltransferase inhibition; human liver microsomes; drug-drug interaction

\section{Introduction}

Honokiol, also known as (2-(4-hydroxy-3-prop-2-enyl-phenyl)-4-prop-2-enyl-phenol, Figure 1), is a biologically active component with antioxidative [1-3], anti-inflammatory [4-8], antithrombotic [9], neuroprotective [10,11], antinociceptive [12,13], antidepressant-like [14], and antitumor [15-21] activities isolated from Magnolia officinalis, Magnolia grandiflora and other plants. Botanical drugs are widely used by global populations for the prevention and treatment of common illnesses [22]. However, many herb-drug interactions resulting from concurrent use of herbal drugs with prescription and over-the-counter drugs may cause adverse reactions such as toxicity and treatment failure [23,24]. The underlying mechanisms of herb-drug interactions typically involve inhibition or induction of cytochrome P450 (CYP) enzymes, UDP-glucuronosyltransferase (UGT) enzymes, and drug transporters [25-29]. Specifically, St. John's wort (Hypericum perforatum), ginkgo (Ginkgo biloba), ginseng (Panax ginseng), milk thistle (Silybum marianum), and licolice (Glycyrrhiza glabra) have all been reported to interact with anticoagulants, antiretroviral drugs, anticancer drugs, immunosuppressants, or antidepressants [30-33]. In addition, bergamotin, a major furanocoumarin found in grapefruit juice, has been reported to increase the blood concentration of drugs by inhibiting hepatic CYP3A activity, thereby enhancing the toxicity of drugs such as simvastatin, felodipine, and cyclosporin [34-36]. Therefore, it is necessary to evaluate herb-drug interactions early in order to prevent potentially dangerous clinical outcomes.

Figure 1. Chemical structure of honokiol.

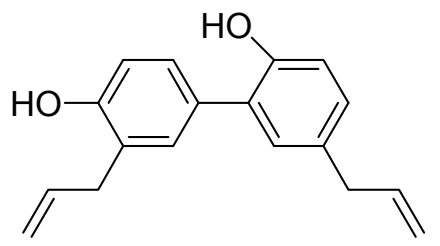

To the best of our knowledge, there have been no previous studies that have evaluated the inhibitory effects of honokiol on human CYP and UGT enzymes. In this study, the effect of honokiol on the activity of eight major human CYPs and four major human UGTs were examined using pooled human liver microsomes to evaluate the possibility of honokiol-drug interactions.

\section{Results and Discussion}

The inhibitory effect of honokiol on eight major human CYP enzymes and four major human UGT enzymes were evaluated using a cocktail of CYP probe substrates and each UGT probe substrate in human liver microsomes, respectively. Honokiol potently inhibited CYP1A2-catalyzed phenacetin $O$-deethylation, CYP2C8-catalyzed amodiaquine $N$-deethylation, CYP2C9-catalyzed diclofenac 4-hydroxylation, and CYP2C19-catalyzed [S]-mephenytoin 4-hydroxylation with $\mathrm{IC}_{50}$ values of 2.1, 
8.9, 4.1, and $2.2 \mu \mathrm{M}$, respectively (Table 1). Honokiol moderately inhibited CYP2B6-mediated bupropion hydroxylation and CYP2D6-mediated bufuralol 1'-hydroxylation with $\mathrm{IC}_{50}$ values of 13.8 and $14.0 \mu \mathrm{M}$, respectively. Honokiol weakly inhibited CYP3A-mediated midazolam 1'-hydroxylation with $\mathrm{IC}_{50}$ values of $97.3 \mu \mathrm{M}$. This was not an unusual finding, given that obovatol, a biphenyl ether lignan, also exhibits an inhibitory effect towards CYP1A2, CYP2B6, CYP2C8, CYP2C9, and CYP2C19 with $\mathrm{IC}_{50}$ values of $4.4,13.9,11.1,3.3$, and $0.8 \mu \mathrm{M}$, respectively [37]. At $100 \mu \mathrm{M}$, honokiol produced negligible inhibition of CYP2A6-mediated coumarin 7-hydroxylation. The inhibitory potencies of honokiol were not significantly affected after a 30 min preincubation with human liver microsomes in the presence of NADPH (Table 1), indicating that honokiol does not inhibit CYPs in a time-dependent manner.

Table 1. Effect of honokiol on CYP metabolic activity in pooled human liver microsomes (H161).

\begin{tabular}{lccc}
\hline \multicolumn{1}{c}{ CYP activity } & CYP & \multicolumn{2}{c}{ IC $_{\mathbf{5 0}}(\boldsymbol{\mu M})$ of honokiol } \\
\cline { 3 - 4 } & & no preincubation & with preincubation * \\
\hline Phenacetin $O$-deethylation & $1 \mathrm{~A} 2$ & 2.1 & 4.7 \\
Coumarin 7-hydroxylation & $2 \mathrm{~A} 6$ & No inhibition & No inhibition \\
Bupropion hydroxylation & $2 \mathrm{~B} 6$ & 13.8 & 20.8 \\
Amodiaquine $N$-deethylation & $2 \mathrm{C} 8$ & 8.9 & 15.5 \\
Diclofenac 4-hydroxylation & $2 \mathrm{C} 9$ & 4.1 & 3.9 \\
$S$-Mephenytoin 4'-hydroxylation & $2 \mathrm{C} 19$ & 2.2 & 2.9 \\
Bufuralol 1'-hydroxylation & $2 \mathrm{D} 6$ & 14.0 & 38.1 \\
Midazolam 1'-hydroxylation & $3 \mathrm{~A} 4$ & 97.3 & 45.8 \\
* Honokiol was preincubated for 30 min in the presence of NADPH before the addition of substrate. No \\
inhibition: inhibition less than $50 \%$ at $100 \mu \mathrm{M}$ of honokiol. The substrate cocktail concentrations used for the \\
assessment of IC 50 were as follows: $50 \mu \mathrm{M}$ phenacetin, $2.5 \mu \mathrm{M}$ coumarin, $2.5 \mu \mathrm{M}$ amodiaquine, $10 \mu \mathrm{M}$ diclofenac, \\
$100 \mu \mathrm{M}[S]$-mephenytoin, $5.0 \mu \mathrm{M}$ bufuralol, and $2.5 \mu \mathrm{M}$ midazolam. Inhibition of CYP2B6 activity was \\
separately evaluated using $50 \mu \mathrm{M}$ bupropion. The data represent the average of three determinations.
\end{tabular}

In inhibition studies, the apparent $K_{\mathrm{i}}$ value is a better parameter for defining the interaction of an inhibitor with a particular enzyme. The $K_{\mathrm{i}}$ values and inhibition types (competitive, noncompetitive, uncompetitive, or mixed) for honokiol were determined using Lineweaver plots, Dixon plots, and secondary reciprocal plots, and the results are summarized in Table 2 and Figure 2. Honokiol noncompetitively inhibited CYP1A2-catalyzed phenacetin $O$-deethylation with a $K_{\mathrm{i}}$ value of $1.2 \mu \mathrm{M}$. Honokiol also competitively inhibited CYP2C9-catalyzed diclofenac 4-hydroxylation $\left(K_{\mathrm{i}}, 0.54 \mu \mathrm{M}\right)$, CYP2C19-catalyzed $[S]$-mephenytoin $\quad 4$-hydroxylation $\quad\left(K_{\mathrm{i}}, \quad 0.57 \mu \mathrm{M}\right), \quad$ CYP2C8-catalyzed amodiaquine $N$-deethylation $\left(K_{\mathrm{i}}, 4.9 \mu \mathrm{M}\right)$, CYP2B6-catalyzed bupropion hydroxylation $\left(K_{\mathrm{i}}, 17.5 \mu \mathrm{M}\right)$, and CYP2D6-mediated bufuralol 1'-hydroxylation $\left(K_{\mathrm{i}}, 12.0 \mu \mathrm{M}\right)$. 
Table 2. $K_{\mathrm{i}}$ values for the inhibition of CYP1A2, CYP2B6, CYP2C8, CYP2C9, CYP2C19, CYP2D6, and UGT1A9 activities by honokiol in pooled human liver microsomes (H161).

\begin{tabular}{clcc}
\hline Enzymes & \multicolumn{1}{c}{ Marker reactions } & $\boldsymbol{K}_{\mathbf{i}}(\mu \mathbf{M})$ & Inhibition mode \\
\hline CYP1A2 & Phenacetin $O$-deethylation & 1.2 & noncompetitive \\
CYP2B6 & Bupropion hydroxylation & 17.5 & competitive \\
CYP2C8 & Amodiaquine $N$-deethylation & 4.9 & competitive \\
CYP2C9 & Diclofenac 4-hydroxylation & 0.54 & competitive \\
CYP2C19 & S-Mephenytoin 4'-hydroxylation & 0.57 & competitive \\
CYP2D6 & Bufuralol 1'-hydroxylation & 12.0 & competitive \\
UGT1A9 & Propofol glucuronidation & 0.3 & competitive \\
\hline
\end{tabular}

Figure 2. Representative Dixon plots for the inhibitory effects of honokiol on (a) CYP1A2-catalyzed phenacetin $O$-deethylation, (b) CYP2B6-catalyzed bupropion hydroxylation, (c) CYP2C8-catalyd amodiaquine $N$-deethylation, (d) CYP2C9-catalyzed diclofenac 4-hydroxylation, (e) CYP2C19-catalyzed [S]-mephenytoin 4-hydroxylation, and (f) CYP2D6-catalyzed bufuralol 1'-hydroxylation in pooled human liver microsomes (H161). Each symbol represents the substrate concentration: (a) phenacetin $10 \mu \mathrm{M}(\nabla)$, $20 \mu \mathrm{M}(\bigcirc), 40 \mu \mathrm{M}(\triangle), 80 \mu \mathrm{M}(\square)$, (b) bupropion $10 \mu \mathrm{M}(\nabla), 20 \mu \mathrm{M}(\bigcirc), 40 \mu \mathrm{M}(\triangle)$, $80 \mu \mathrm{M}(\square)$, (c) amodiaquine, $1.0 \mu \mathrm{M}(\nabla), 2.0 \mu \mathrm{M}(\bigcirc), 4.0 \mu \mathrm{M}(\triangle), 8.0 \mu \mathrm{M}(\square)$; (d) diclofenac, $1.25 \mu \mathrm{M}(\nabla), 2.5 \mu \mathrm{M}(\bigcirc), 5 \mu \mathrm{M}(\triangle), 10 \mu \mathrm{M}(\square)$; (e) [S]-mephenytoin, $20 \mu \mathrm{M}(\nabla), 40 \mu \mathrm{M}(\bigcirc), 80 \mu \mathrm{M}(\triangle), 160 \mu \mathrm{M}(\square)$; (f) bufuralol, $1.0 \mu \mathrm{M}(\nabla), 2.0 \mu \mathrm{M}(\bigcirc)$, $4.0 \mu \mathrm{M}(\triangle)$. Each data point represents the mean of triplicate experiments.

(a)

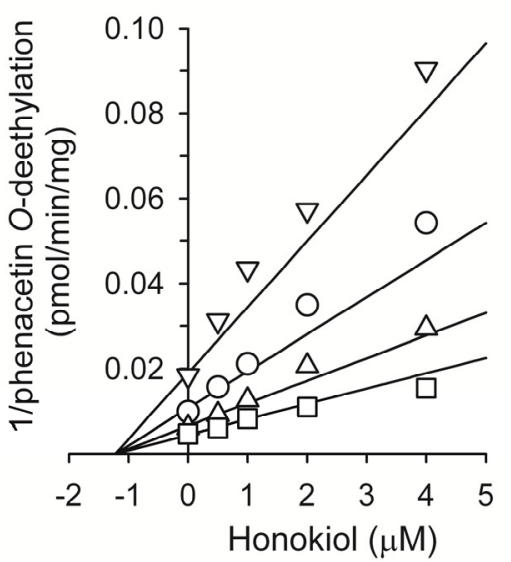

(d)

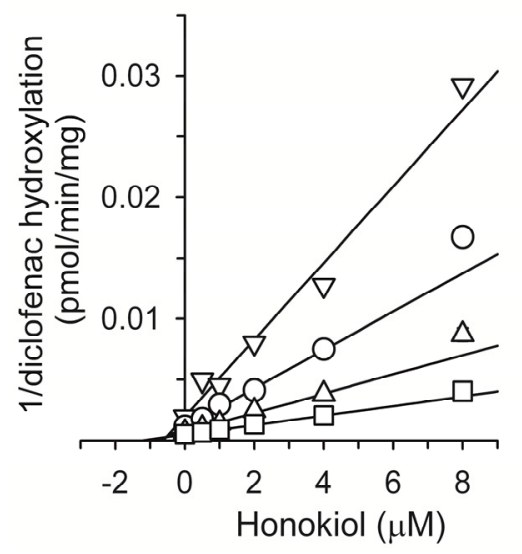

(b)

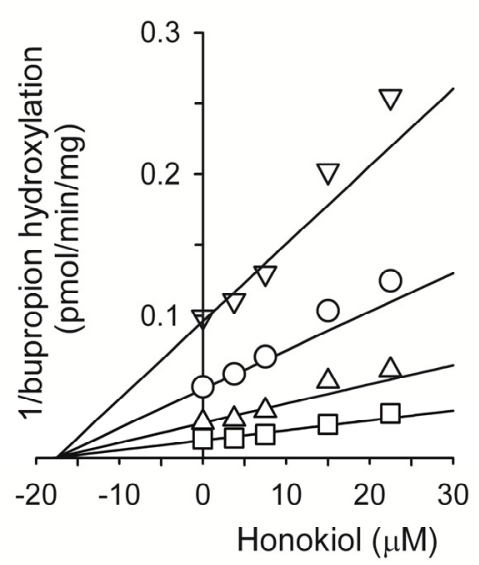

(e)

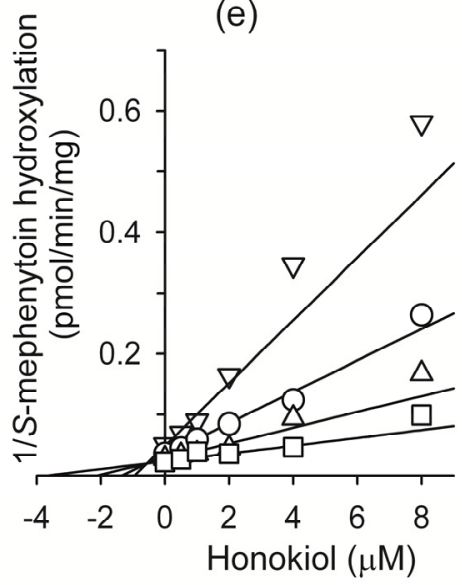

(c)

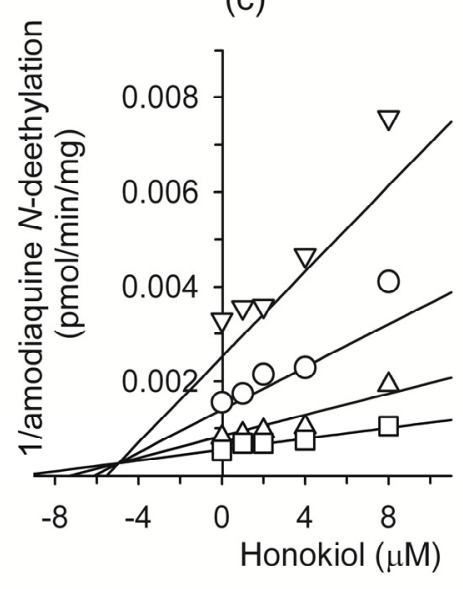

(f)

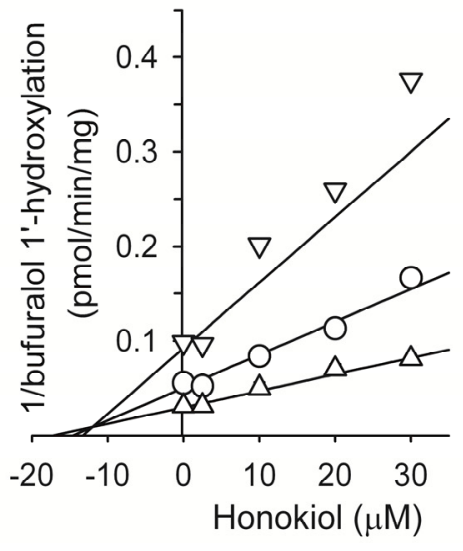


We also evaluated the inhibitory potential of honokiol on the activity of four UGT enzymes (Table 3). Honokiol potently inhibited UGT1A9-catalyzed propofol glucuronidation with $\mathrm{IC}_{50}$ values of $0.98 \mu \mathrm{M}$. Honokiol weakly inhibited UGT1A1-catalyzed 17 $\beta$-estradiol 3-glucuronidation, UGT2B7-catalyzed azidothymidine glucuronidation, and UGT1A4-catalyzed trifluoperazine $\mathrm{N}$-glucuronidation with $\mathrm{IC}_{50}$ values of $50.5,36.4$, and $158.1 \mu \mathrm{M}$, respectively. Honokiol exhibited competitive inhibition for propofol glucuronidation with a $K_{\mathrm{i}}$ value of $0.3 \mu \mathrm{M}$ (Figure 3 and Table 2) and potent propofol glucuronidation inhibitory activity $\left(K_{\mathrm{i}}, 0.3 \mu \mathrm{M}\right)$ similar to that of the selective UGT1A9 inhibitor niflumic acid $\left(K_{\mathrm{i}}, 0.1 \sim 0.4 \mu \mathrm{M}\right)$ [38]. Thus, in order to avoid drug interactions honokiol, it is recommended that it should be used carefully with drugs metabolized by UGT1A9, such as S-etodolac [39], entacapone [40], gaboxadol [41], retigabine [42], and scopoletin [43].

Table 3. Effect of honokiol on UGT metabolic activity in pooled human liver microsomes (H161).

\begin{tabular}{clc}
\hline UGT & \multicolumn{1}{c}{ Marker enzyme } & IC $_{\mathbf{5 0}}(\mu \mathbf{M})$ \\
\hline UGT1A1 & 17ß-estradiol 3-glucuronidation & 50.5 \\
UGT1A4 & trifluoperazine $N$-glucuronidation & 158.1 \\
UGT1A9 & propofol glucuronidation & 0.96 \\
UGT2B7 & azidothymidine glucuronidation & 36.4 \\
\hline
\end{tabular}

Figure 3. Representative Dixon plots for the inhibitory effects of honokiol on UGT1A9-catalyzed propofol glucuronidation in pooled human liver microsomes (H161). Each symbol represents the substrate concentration: propofol, $5 \mu \mathrm{M}(\nabla), 10 \mu \mathrm{M}(\bigcirc)$, $20 \mu \mathrm{M}(\triangle), 40 \mu \mathrm{M}(\square)$. Each data point represents the mean of triplicate experiments.

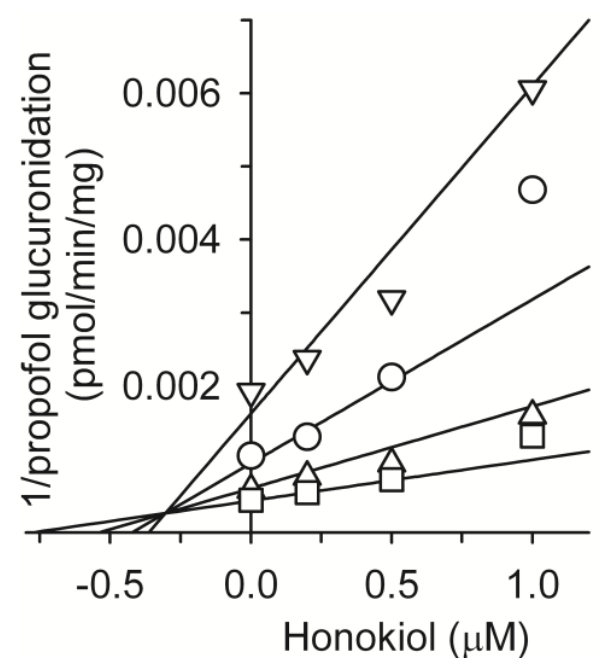

Honokiol showed potent inhibitory activity against diclofenac hydroxylation $\left(K_{\mathrm{i}}, 0.54 \mu \mathrm{M}\right)$ similar to the selective CYP2C9 inhibitor sulfaphenazole $\left(\mathrm{IC}_{50}=0.8 \mu \mathrm{M}\right)$ [44], indicating that honokiol should also be used carefully with CYP2C9 substrates such as celecoxib, diclofenac, glyburide, losartan, tolbutamide, torasemide, and $S$-warfarin to avoid drug interactions [45].

Honokiol was shown to be a potent competitive inhibitor of CYP2C19, with a $K_{\mathrm{i}}$ value of $0.57 \mu \mathrm{M}$, indicating that honokiol should be used carefully with CYP2C19 substrates such as diazepam, phenytoin, amitriptyline, imipramine, lansoprazole, and omeprazole in order to avoid drug 
interactions [46]. In addition, some natural compounds, including anthocyanidin [47], beauvericin [48], corydaline [49], eupatilin [50], and ursolic acid [51] have demonstrated strong inhibition of CYP2C19.

Honokiol was found to be a potent noncompetitive inhibitor of CYP1A2 with a $K_{\mathrm{i}}$ value of $1.2 \mu \mathrm{M}$, indicating that honokiol should be used carefully with drugs metabolized by CYP1A2 such as antipsychotics (clozapine and haloperidol), antiathmatics (theophylline and zileuton), and antidepressants (amitriptyline and clomipramine) in order to avoid drug interactions [46]. Further, several natural compounds including luotonin [52], mollugin [53], and astragaloside IV [54] have been shown to strongly inhibit CYP1A2.

Honokiol was found to be a competitive inhibitor of CYP2C8, with a $K_{\mathrm{i}}$ value of $4.9 \mu \mathrm{M}$, indicating that it should be used carefully with drugs metabolized by CYP2C8 such as cerivastatin, paclitaxel, repaglinide, sorafenib, and torsemide to avoid drug interactions [55]. Its potency was comparable to that of selective CYP2C8 inhibitors such as quercetin $\left(K_{\mathrm{i}}, 2.0 \mu \mathrm{M}\right)$ [56], montelukast $\left(K_{\mathrm{i}}, 0.0092-0.15 \mu \mathrm{M}\right)$ [57], and gemfibrozil glucuronide $\left(K_{\mathrm{i}}, 20-52 \mu \mathrm{M}\right)$ [58].

Herbal preparations containing honokiol may also affect CYP1A2, CYP2C8, CYP2C9, CYP2C19, and UGT1A9 activities. At present, there is no available data on the pharmacokinetics of honokiol in humans, which are indispensable for the prediction of the drug-drug interaction potential of honokiol. These in vitro results suggest however that honokiol should be examined for potential pharmacokinetic drug interactions in vivo due to its inhibition of CYP1A2, CYP2C8, CYP2C9, CYP2C19, and UGT1A9 activities based on $K_{\mathrm{i}}$ values of $0.3-4.9 \mu \mathrm{M}$.

\section{Experimental}

\subsection{Materials}

Acetaminophen, alamethicin, coumarin, diclofenac, 17 $\beta$-estradiol, 17 $\beta$-estradiol 3-glucuronide, glucose-6-phosphate, glucose-6-phosphate dehydrogenase, 7-hydroxycoumarin, midazolam, $\beta$-nicotinamide adenine dinucleotide phosphate (NADP), the reduced form of NADP (NADPH), phenacetin, propofol, trifluoperazine, honokiol ( $>98 \%$ by HPLC), and uridine-5-diphospho-glucuronic acid trisoduim salt (UDPGA) were purchased from Sigma-Aldrich (St. Louis, MO, USA). Pooled human liver microsomes (H161), ${ }^{13} \mathrm{C}_{2},{ }^{15} N$-acetaminophen, bufuralol, $N$-desethylamodiaquine, 1'-hydroxybufuralol, $\mathrm{d}_{9}$-1'-hydroxybufuralol maleate, 4-hydroxy-diclofenac, 4-hydroxymephenytoin, 1'-hydroxymidazolam, and [S]-mephenytoin were obtained from BD Gentest Co. (Woburn, MA, USA). Azidothymidine, azidothymidine glucuronide, bupropion, hydroxybupropion, and propofol glucuronide were obtained from Toronto Research Chemicals (Toronto, ON, Canada). Acetonitrile and methanol (HPLC grade) were obtained from Burdick \& Jackson Inc. (Muskegon, MI, USA). All other chemicals were of the highest quality available.

\subsection{Inhibitory Effect of Honokiol on Eight Major CYP Activities in Human Liver Microsomes}

The inhibitory potential ( $\mathrm{IC}_{50}$ values) of honokiol on CYP activities was evaluated in pooled human liver microsomes using liquid chromatography-tandem mass spectrometry (LC-MS/MS). The incubation mixtures were prepared in a total volume of $100 \mu \mathrm{L}$ as follows: pooled human liver microsomes $(0.2 \mathrm{mg} / \mathrm{mL}), 1.0 \mathrm{mM} \mathrm{NADPH}, 10 \mathrm{mM} \mathrm{MgCl}_{2}, 50 \mathrm{mM}$ potassium phosphate buffer 
( $\mathrm{pH}$ 7.4), various concentrations of honokiol $(0.05-100 \mu \mathrm{M})$ and a cocktail mixture of seven CYP probe substrates or bupropion, a CYP2B6-selective substrate, as reported previously [50]. Honokiol was dissolved in acetonitrile. The substrates were used at concentrations approximately equal to or less than that of their respective $K_{\mathrm{m}}$ values: $50 \mu \mathrm{M}$ phenacetin for CYP1A2, $2.5 \mu \mathrm{M}$ coumarin for CYP2A6, $50 \mu \mathrm{M}$ bupropion for CYP2B6, $2.5 \mu \mathrm{M}$ amodiaquine for CYP2C8, $10 \mu \mathrm{M}$ diclofenac for CYP2C9, $100 \mu \mathrm{M}[S]$-mephenytoin for CYP2C19, $5 \mu \mathrm{M}$ bufuralol for CYP2D6, and $2.5 \mu \mathrm{M}$ midazolam for CYP3A4. After a 3 min preincubation at $37{ }^{\circ} \mathrm{C}$, the reactions were initiated by addition of an NADP generating system and incubated for $15 \mathrm{~min}$ at $37{ }^{\circ} \mathrm{C}$ in a shaking water bath. The reaction was then stopped by placement of the tubes on ice and adding $100 \mu \mathrm{L}$ of ice-cold methanol containing internal standards $\left({ }^{13} \mathrm{C}_{2},{ }^{15} \mathrm{~N}\right.$-acetaminophen for acetaminophen and $\mathrm{N}$-deethylamodiaquine, and $\mathrm{d}_{9}$-1-hydroxybufuralol for 4-hydroxydiclofenac, 4-hydroxybupropion, 7-hydroxycoumarin, 4-hydroxymephenytoin, 1'-hydroxybufuralol, and 1'-hydroxymidazolam). The incubation mixtures were then centrifuged at $13,000 \times g$ for $4 \mathrm{~min}$. All incubations were performed in triplicate, and average values were used.

For evaluation of time-dependent inhibition of CYP activities, various concentrations of honokiol $(0.05-100 \mu \mathrm{M})$ were pre-incubated for $30 \mathrm{~min}$ with human liver microsomes in the presence of NADPH. The reaction was initiated by the addition of the cocktail containing seven CYP probe substrates and bupropion.

The metabolites formed from the seven CYP cocktail substrates were simultaneously determined according to our previously described LC-MS/MS method with minor modification [50]; the concentration of 4-hydroxybupropion for CYP2B6 activity was quantified separately by LC-MS/MS. A tandem mass spectrometer (TSQ Quantum Access, Thermo Scientific, San Jose, CA, USA) coupled with a Nanospace SI-2 LC system (Tokyo, Japan) was used. The column and autosampler temperatures were $50{ }^{\circ} \mathrm{C}$ and $6{ }^{\circ} \mathrm{C}$, respectively. The mass spectrometer was equipped with an electrospray ionization (ESI) source and operated in positive ion mode. The ESI source settings for ionization of the metabolites were as follows: capillary voltage, $4200 \mathrm{~V}$; vaporizer temperature, $350{ }^{\circ} \mathrm{C}$; capillary temperature $330{ }^{\circ} \mathrm{C}$; sheath gas pressure, $35 \mathrm{psi}$; auxiliary gas pressure, 15 psi. Quantification was performed by selected reaction monitoring $(\mathrm{SRM})$ of $[\mathrm{M}+\mathrm{H}]^{+}$ions and the related product ions for each metabolite. SRM transitions for the metabolites and internal standards have been described previously by our group [50]. Analytical data were processed using Xcalibur ${ }^{\circledR}$ software (Thermo Scientific).

\subsection{Inhibitory Effect of Honokiol on Four UGT Activities in Human Liver Microsomes}

The inhibitory potency ( $\mathrm{IC}_{50}$ value) of honokiol on UGT1A1-catalyzed 17 $\beta$-estradiol 3-glucuronidation, UGT1A4-catalyzed trifluoperazine glucuronidation, UGT1A9-catalyzed propofol glucuronidation, and UGT2B7-catalyzed azidothymidine glucuronidation activities was determined in pooled human liver microsomes by LC-MS/MS [48]. Briefly, incubation mixtures were prepared in a total volume of $100 \mu \mathrm{L}$ as follows: pooled human liver microsomes $(0.2 \mathrm{mg} / \mathrm{mL}$ for $17 \beta$-estradiol, trifluoperazine, and azidothymidine; $0.1 \mathrm{mg} / \mathrm{mL}$ for propofol), $25 \mu \mathrm{g} / \mathrm{mL}$ alamethicin, $10 \mathrm{mM} \mathrm{MgCl}_{2}$, $50 \mathrm{mM}$ tris buffer ( $\mathrm{pH} 7.4)$, each UGT-isoform specific probe substrate $(20 \mu \mathrm{M}$ 17ß-estradiol for UGT1A1, $5 \mu \mathrm{M}$ trifluoperazine for UGT1A4, $10 \mu \mathrm{M}$ propofol for UGT1A9, or $100 \mu \mathrm{M}$ 
azidothymidine for UGT2B7), and various concentrations of honokiol (1-200 $\mu \mathrm{M}$ for UGT1A1, UGT1A4, and UGT2B7; 0.01-2 $\mu \mathrm{M}$ for UGT1A9). Reactions were initiated by the addition of UDPGA (final concentration, $5 \mathrm{mM}$ ), and incubations were carried out at $37{ }^{\circ} \mathrm{C}$ in a shaking water bath for $30 \mathrm{~min}$. Reactions were terminated by adding $100 \mu \mathrm{L}$ of ice-cold methanol containing an internal standard $(500 \mathrm{ng} / \mathrm{mL}$ ezetimibe for $17 \beta$-estradiol 3-glucuronide and propofol glucuronide; $30 \mathrm{ng} / \mathrm{mL}$ meloxicam for trifluoperazine glucuronide and azidothymidine glucuronide). The incubation mixtures were then centrifuged at $13,000 \times g$ for $4 \mathrm{~min}$, followed by dilution of $30 \mu \mathrm{L}$ of the supernatant with $70 \mu \mathrm{L}$ of water. An aliquot $(5 \mu \mathrm{L})$ was injected onto the LC-MS/MS. All incubations were performed in triplicate and the mean values were used. Glucuronides produced from UGT isoform-specific substrates were determined by LC-MS/MS [49].

\subsection{Kinetic Analysis}

In order to determine $K_{\mathrm{i}}$ values of honokiol for CYP1A2, CYP2B6, CYP2C8, CYP2C9, CYP2C19, and CYP2D6 enzymes, human liver microsomes $(0.1 \mathrm{mg} / \mathrm{mL}$ for CYP2C, CYP2C9, $0.15 \mathrm{mg} / \mathrm{mL}$ for CYP2B6, and $0.2 \mathrm{mg} / \mathrm{mL}$ for CYP1A2, CYP2C19, and CYP2D6) were incubated with various concentrations of substrates $(10-80 \mu \mathrm{M}$ phenacetin for CYP1A2, 10-80 $\mu \mathrm{M}$ bupropion for CYP2B6, 1-8 $\mu \mathrm{M}$ amodiaquine for CYP2C8, 1.25-10 $\mu \mathrm{M}$ diclofenac for CYP2C9, 20-160 $\mu \mathrm{M}[S]$-mephenytoin for CYP2C19, and 1-4 $\mu \mathrm{M}$ bufuralol for CYP2D6, respectively), $1 \mathrm{mM} \mathrm{NADPH,} 10 \mathrm{mM} \mathrm{MgCl} 2$, and various concentrations of honokiol in $50 \mathrm{mM}$ potassium phosphate buffer $(\mathrm{pH} 7.4)$ in a total incubation volume of $100 \mu \mathrm{L}$. The reactions were initiated by the addition of NADPH at $37{ }^{\circ} \mathrm{C}$ and stopped after $10 \mathrm{~min}$ by placing the incubation tubes on ice and adding $100 \mu \mathrm{L}$ of ice-cold methanol containing an internal standard $\left(150 \mathrm{ng} / \mathrm{mL}^{13} \mathrm{C}_{2},{ }^{15} \mathrm{~N}\right.$-acetaminophen for acetaminophen and $N$-desethylamodiaquine; $10 \mathrm{ng} / \mathrm{mL} \mathrm{d}$-1'-hydroxybufuralol for hydroxybupropion, 4-hydroxydiclofenac, 4-hydroxymephenytoin, and 1'-hydroxybufuralol). The incubation mixtures were centrifuged at $13,000 \times g$ for $4 \mathrm{~min}$, and the supernatants were diluted as follows: dilution of $20 \mu \mathrm{L}$ supernatant with $180 \mu \mathrm{L}$ of $25 \%$ methanol for CYP2C8; dilution of $50 \mu \mathrm{L}$ supernatant with $50 \mu \mathrm{L}$ of water for CYP2C9, CYP2C19, CYP2D6, and CYP1A2; and dilution of $20 \mu \mathrm{L}$ supernatant with $80 \mu \mathrm{L}$ of water for CYP2B6. Aliquots $(5 \mu \mathrm{L})$ of the diluted supernatants were then analyzed by LC-MS/MS.

For the determination of $K_{\mathrm{i}}$ values for UGT1A9, human liver microsomes $(0.1 \mathrm{mg} / \mathrm{mL})$ were incubated with various concentrations of propofol $(5-40 \mu \mathrm{M}), 5 \mathrm{mM}$ UDPGA, $25 \mu \mathrm{g} / \mathrm{mL}$ alamethicin, $10 \mathrm{mM} \mathrm{MgCl}_{2}$, and various concentrations of honokiol $(0-1 \mu \mathrm{M})$ in $50 \mathrm{mM}$ Tris buffer $(\mathrm{pH} 7.4)$ in a total incubation volume of $100 \mu \mathrm{L}$. The reactions were initiated by addition of UDPGA at $37{ }^{\circ} \mathrm{C}$ and stopped after 30 min by placing the incubation tubes on ice and adding $100 \mu \mathrm{L}$ of $500 \mathrm{ng} / \mathrm{mL}$ ezetimibe (internal standard) in ice-cold methanol. The incubation mixtures were then centrifuged at $13,000 \times g$ for $4 \mathrm{~min}$, after which $30 \mu \mathrm{L}$ of the supernatant was diluted with $70 \mu \mathrm{L}$ of water. Aliquots $(5 \mu \mathrm{L})$ were then analyzed by LC-MS/MS.

\subsection{Data Analysis}

$\mathrm{IC}_{50}$ values (concentration of the inhibitor causing a 50\% inhibition of the original enzyme activity) were calculated using Sigma Plot 8.0 (Systat Software, Inc., San Jose, CA, USA). The apparent kinetic 
parameters for inhibitory potential ( $K_{\mathrm{i}}$ values) were estimated from the fitted curves using Enzyme Kinetics Ver. 1.1 software (Systat Software Inc.).

\section{Conclusions}

The effect of honokiol on eight CYPs and four UGTs was determined across a wide range of substrates and honokiol concentrations using human liver microsomes. CYP1A2, CYP2C8, CYP2C9, CYP2C19, and UGT1A9 activities were potently inhibited by honokiol upon incubation in microsomes. Honokiol weakly inhibited CYP2B6-catalyzed bupropion hydroxylation, CYP2D6-catalyzed bufuralol 1'-hydroxylation, CYP3A-catalyzed midazolam hydroxylation, UGT1A1-catalyzed 17ß-estradiol 3-glucuronidation, and UGT2B7-catalyzed azidothymidine glucuronidation in a dose-dependent manner. These results indicate that honokiol has the potential to cause pharmacokinetic drug interactions with other co-administered drugs metabolized by CYP1A2, CYP2C8, CYP2C9, CYP2C19, and UGT1A9. However, it is important to note that the inhibition of CYP activities in vitro does not necessarily translate into drug interactions in clinical situations. Thus, clinical trials to evaluate the inhibitory effects of honokiol on CYP1A2, CYP2C8, CYP2C9, CYP2C19, and UGT1A9 should be conducted.

\section{Acknowledgments}

This study was supported by a grant (A001100476) from the Regional Industrial Technology Development Program through the Ministry of Trade, Industry and Energy of Korea to Huons Co., Ltd., and by The Catholic University of Korea, 2012 (M2012B000200024).

\section{Conflicts of Interest}

The authors declare no conflict of interest.

\section{References}

1. Cui, H.S.; Huang, L.S.; Sok, D.E.; Shin, J.; Kwon, B.M.; Youn, U.J.; Bae, K. Protective action of honokiol, administered orally, against oxidative stress in brain of mice challenged with NMDA. Phytomedicine 2007, 14, 696-700.

2. Dikalov, S.; Losik, T.; Arbiser, J.L. Honokiol is a potent scavenger of superoxide and peroxyl radicals. Biochem. Pharmacol. 2008, 76, 589-596.

3. Shen, J.L.; Man, K.M.; Huang, P.H.; Chen, W.C.; Chen, D.C.; Cheng, Y.W.; Liu, P.L.; Chou, M.C.; Chen, Y.H. Honokiol and magnolol as multifunctional antioxidative molecules for dermatologic disorders. Molecules 2010, 15, 6452-6465.

4. Kim, B.H.; Cho, J.Y. Anti-inflammatory effect of honokiol is mediated by PI3K/Akt pathway suppression. Acta Pharmacol. Sin. 2008, 29, 113-122.

5. Lee, J.; Jung, E.; Park, J.; Jung, K.; Lee, S.; Hong, S.; Park, E.; Kim, J.; Park, S.; Park, D. Anti-inflammatory effects of magnolol and honokiol are mediated through inhibition of the downstream pathway of MEKK-1 in NF-kappaB activation signaling. Planta Med. 2005, 71, 338-343. 
6. Munroe, M.E.; Arbiser, J.L.; Bishop, G.A. Honokiol, a natural plant product, inhibits inflammatory signals and alleviates inflammatory arthritis. J. Immunol. 2007, 179, 753-763.

7. Chao, L.K.; Liao, P.C.; Ho, C.L.; Wang, E.I.; Chuang, C.C.; Chiu, H.W.; Hung, L.B.; Hua, K.F. Anti-inflammatory bioactivities of honokiol through inhibition of protein kinase $\mathrm{C}$, mitogen-activated protein kinase, and the NF-kappaB pathway to reduce LPS-induced TNFalpha and NO expression. J. Agric. Food Chem. 2010, 58, 3472-3478.

8. Munroe, M.E.; Businga, T.R.; Kline, J.N.; Bishop, G.A. Anti-inflammatory effects of the neurotransmitter agonist Honokiol in a mouse model of allergic asthma. J. Immunol. 2010, 185, 5586-5597.

9. Hu, H.; Zhang, X.X.; Wang, Y.Y.; Chen, S.Z. Honokiol inhibits arterial thrombosis through endothelial cell protection and stimulation of prostacyclin. Acta Pharmacol. Sin. 2005, 26, 1063-1068.

10. Hoi, C.P.; Ho, Y.P.; Baum, L.; Chow, A.H. Neuroprotective effect of honokiol and magnolol, compounds from Magnolia officinalis, on beta-amyloid-induced toxicity in PC12 cells. Phytother. Res. 2010, 24, 1538-1542.

11. Lin, Y.R.; Chen, H.H.; Ko, C.H.; Chan, M.H. Neuroprotective activity of honokiol and magnolol in cerebellar granule cell damage. Eur. J. Pharmacol. 2006, 537, 64-69.

12. Matsui, N.; Takahashi, K.; Takeichi, M.; Kuroshita, T.; Noguchi, K.; Yamazaki, K.; Tagashira, H.; Tsutsui, K.; Okada, H.; Kido, Y.; et al. Magnolol and honokiol prevent learning and memory impairment and cholinergic deficit in SAMP8 mice. Brain Res. 2009, 1305, 108-117.

13. Lin, Y.R.; Chen, H.H.; Lin, Y.C.; Ko, C.H.; Chan, M.H. Antinociceptive actions of honokiol and magnolol on glutamatergic and inflammatory pain. J. Biomed. Sci. 2009, 16, 94.

14. Xu, Q.; Yi, L.T.; Pan, Y.; Wang, X.; Li, Y.C.; Li, J.M.; Wang, C.P.; Kong, L.D. Antidepressantlike effects of the mixture of honokiol and magnolol from the barks of Magnolia officinalis in stressed rodents. Prog. Neuropsychopharmacol. Biol. Psychiatry 2008, 32, 715-725.

15. Hahm, E.R.; Arlotti, J.A.; Marynowski, S.W.; Singh, S.V. Honokiol, a constituent of oriental medicinal herb magnolia officinalis, inhibits growth of PC-3 xenografts in vivo in association with apoptosis induction. Clin. Cancer Res. 2008, 14, 1248-1257.

16. Liu, H.; Zang, C.; Emde, A.; Planas-Silva, M.D.; Rosche, M.; Kuhnl, A.; Schulz, C.O.; Elstner, E.; Possinger, K.; Eucker, J. Anti-tumor effect of honokiol alone and in combination with other anti-cancer agents in breast cancer. Eur. J. Pharmacol. 2008, 591, 43-51.

17. Fried, L.E.; Arbiser, J.L., Honokiol, a multifunctional antiangiogenic and antitumor agent. Antioxid. Redox Signal 2009, 11, 1139-1148.

18. Steinmann, P.; Walters, D.K.; Arlt, M.J.; Banke, I.J.; Ziegler, U.; Langsam, B.; Arbiser, J.; Muff, R.; Born, W.; Fuchs, B. Antimetastatic activity of honokiol in osteosarcoma. Cancer 2012, $118,2117-2127$.

19. Tian, W.; Xu, D.; Deng, Y.C. Honokiol, a multifunctional tumor cell death inducer. Pharmazie 2012, 67, 811-816.

20. Kapoor, S. Attenuation of tumor growth by honokiol: An evolving role in oncology. Drug Discov. Ther. 2012, 6, 327-328. 
21. Kaushik, G.; Ramalingam, S.; Subramaniam, D.; Rangarajan, P.; Protti, P.; Rammamoorthy, P.; Anant, S.; Mammen, J.M. Honokiol induces cytotoxic and cytostatic effects in malignant melanoma cancer cells. Am. J. Surg. 2012, 204, 868-873.

22. Chang, J. Medicinal herbs: Drugs or dietary supplements? Biochem. Pharmacol. 2000, 59, 211-219.

23. Zhang, Z.J.; Tan, Q.R.; Tong, Y.; Wang, X.Y.; Wang, H.H.; Ho, L.M.; Wong, H.K.; Feng, Y.B.; Wang, D.; Ng, R.; et al. An epidemiological study of concomitant use of Chinese medicine and antipsychotics in schizophrenic patients: Implication for herb-drug interaction. PLoS One 2011, 6, e17239.

24. Girard, L.; Vohra, S. Herbal Medicine: Biomolecular and Clinical Aspects; Benzie, I.F.F., Wachtel-Galor, S., Eds.; CRC Press: Boca Raton, FL, USA, 2011; Chapter 21, p. 320.

25. Zhou, S.F.; Zhou, Z.W.; Li, C.G.; Chen, X.; Yu, X.; Xue, C.C.; Herington, A. Identification of drugs that interact with herbs in drug development. Drug Discov. Today 2007, 12, 664-673.

26. He, S.M.; Chan, E.; Zhou, S.F. ADME properties of herbal medicines in humans: Evidence, challenges and strategies. Curr. Pharm. Des. 2011, 17, 357-407.

27. Mohamed, M.E.; Frye, R.F. Effects of herbal supplements on drug glucuronidation. Review of clinical, animal, and in vitro studies. Planta Med. 2011, 77, 311-321.

28. Na, D.H.; Ji, H.Y.; Park, E.J.; Kim, M.S.; Liu, K.H.; Lee, H.S. Evaluation of metabolismmediated herb-drug interactions. Arch. Pharm. Res. 2011, 34, 1829-1842.

29. Pao, L.H.; Hu, O.Y.; Fan, H.Y.; Lin, C.C.; Liu, L.C.; Huang, P.W. Herb-drug interaction of 50 Chinese herbal medicines on CYP3A4 activity in vitro and in vivo. Am. J. Chin. Med. 2012, $40,57-73$.

30. Borrelli, F.; Izzo, A.A. Herb-drug interactions with St John's wort (Hypericum perforatum): An update on clinical observations. AAPS J. 2009, 11, 710-727.

31. Wu, J.W.; Lin, L.C.; Tsai, T.H. Drug-drug interactions of silymarin on the perspective of pharmacokinetics. J. Ethnopharmacol. 2009, 121, 185-193.

32. He, S.M.; Yang, A.K.; Li, X.T.; Du, Y.M.; Zhou, S.F. Effects of herbal products on the metabolism and transport of anticancer agents. Expert Opin. Drug Metab. Toxicol. 2010, 6, 1195-1213.

33. Chen, X.W.; Serag, E.S.; Sneed, K.B.; Liang, J.; Chew, H.; Pan, S.Y.; Zhou, S.F. Clinical herbal interactions with conventional drugs: From molecules to maladies. Curr. Med. Chem. 2011, 18, 4836-4850.

34. Le Goff-Klein, N.; Koffel, J.C.; Jung, L.; Ubeaud, G. In vitro inhibition of simvastatin metabolism, a HMG-CoA reductase inhibitor in human and rat liver by bergamottin, a component of grapefruit juice. Eur. J. Pharm. Sci. 2003, 18, 31-35.

35. Bailey, D.G.; Dresser, G.K.; Bend, J.R. Bergamottin, lime juice, and red wine as inhibitors of cytochrome P450 3A4 activity: Comparison with grapefruit juice. Clin. Pharmacol. Ther. 2003, 73, 529-537.

36. Johnston, P.E.; Milstone, A. Probable interaction of bergamottin and cyclosporine in a lung transplant recipient. Transplantation 2005, 79, 746.

37. Joo, J.; Lee, D.; Wu, Z.; Shin, J.H.; Lee, H.S.; Kwon, B.M.; Huh, T.L.; Kim, Y.W.; Lee, S.J.; Kim, T.W.; et al. In vitro metabolism of obovatol and its effect on cytochrome P450 enzyme activities in human liver microsomes. Biopharm. Drug Dispos. 2013, 34, 195-202. 
38. Miners, J.O.; Bowalgaha, K.; Elliot, D.J.; Baranczewski, P.; Knights, K.M. Characterization of niflumic acid as a selective inhibitor of human liver microsomal UDP-glucuronosyltransferase 1A9: Application to the reaction phenotyping of acetaminophen glucuronidation. Drug Metab. Dispos. 2011, 39, 644-652.

39. Tougou, K.; Gotou, H.; Ohno, Y.; Nakamura, A. Stereoselective glucuronidation and hydroxylation of etodolac by UGT1A9 and CYP2C9 in man. Xenobiotica 2004, 34, 449-461.

40. Lautala, P.; Ethell, B.T.; Taskinen, J.; Burchell, B. The specificity of glucuronidation of entacapone and tolcapone by recombinant human UDP-glucuronosyltransferases. Drug Metab. Dispos. 2000, 28, 1385-1389.

41. Chu, X.Y.; Liang, Y.; Cai, X.; Cuevas-Licea, K.; Rippley, R.K.; Kassahun, K.; Shou, M.; Braun, M.P.; Doss, G.A.; Anari, M.R.; et al. Metabolism and renal elimination of gaboxadol in humans: Role of UDP-glucuronosyltransferases and transporters. Pharm. Res. 2009, 26, 459-468.

42. Borlak, J.; Gasparic, A.; Locher, M.; Schupke, H.; Hermann, R. N-Glucuronidation of the antiepileptic drug retigabine: Results from studies with human volunteers, heterologously expressed human UGTs, human liver, kidney, and liver microsomal membranes of Crigler-Najjar type II. Metabolism 2006, 55, 711-721.

43. Luukkanen, L.; Taskinen, J.; Kurkela, M.; Kostiainen, R.; Hirvonen, J.; Finel, M. Kinetic characterization of the 1A subfamily of recombinant human UDP-glucuronosyltransferases. Drug Metab. Dispos. 2005, 33, 1017-1026.

44. Newton, D.J.; Wang, R.W.; Lu, A.Y. Cytochrome P450 inhibitors. Evaluation of specificities in the in vitro metabolism of therapeutic agents by human liver microsomes. Drug Metab. Dispos. 1995, 23, 154-158.

45. Zhou, S.F.; Zhou, Z.W.; Yang, L.P.; Cai, J.P. Substrates, inducers, inhibitors and structure-activity relationships of human Cytochrome P450 2C9 and implications in drug development. Curr. Med. Chem. 2009, 16, 3480-3675.

46. Cytochrome P450 Drug Interaction Table. Available online: http://medicine.iupui.edu/clinpharm/ddis/ (accessed on 12 January 2009).

47. Sand, P.G.; Dreiseitel, A.; Stang, M.; Schreier, P.; Oehme, A.; Locher, S.; Hajak, G. Cytochrome P450 2C19 inhibitory activity of common berry constituents. Phytother. Res. 2010, 24, 304-307.

48. Mei, L.; Zhang, L.; Dai, R. An inhibition study of beauvericin on human and rat cytochrome P450 enzymes and its pharmacokinetics in rats. J. Enzyme Inhib. Med. Chem. 2009, 24, 753-762.

49. Ji, H.Y.; Liu, K.H.; Lee, H.; Im, S.R.; Shim, H.J.; Son, M.; Lee, H.S. Corydaline inhibits multiple cytochrome P450 and UDP-glucuronosyltransferase enzyme activities in human liver microsomes. Molecules 2011, 16, 6591-6602.

50. Ji, H.Y.; Kim, S.Y.; Kim, D.K.; Jeong, J.H.; Lee, H.S. Effects of eupatilin and jaceosidin on cytochrome p450 enzyme activities in human liver microsomes. Molecules 2010, 15, 6466-6475.

51. Kim, K.A.; Lee, J.S.; Park, H.J.; Kim, J.W.; Kim, C.J.; Shim, I.S.; Kim, N.J.; Han, S.M.; Lim, S. Inhibition of cytochrome P450 activities by oleanolic acid and ursolic acid in human liver microsomes. Life Sci. 2004, 74, 2769-2779.

52. Jahng, Y.; Kwon, O.K.; Lee, S. In vitro inhibitory effect of luotonin A on human CYP1A. Arch. Pharm. Res. 2012, 35, 2199-2203. 
53. Kim, H.; Choi, H.K.; Jeong, T.C.; Jahng, Y.; Kim, D.H.; Lee, S.H.; Lee, S. Selective inhibitory effects of mollugin on CYP1A2 in human liver microsomes. Food Chem. Toxicol. 2013, 51, 33-37.

54. Zhang, Y.H.; Zhang, Y.J.; Guo, Y.L.; Li, W.J.; Yu, C. Astragaloside IV inhibited the activity of CYP1A2 in liver microsomes and influenced theophylline pharmacokinetics in rats. J. Pharm. Pharmacol. 2013, 65, 149-155.

55. Lai, X.S.; Yang, L.P.; Li, X.T.; Liu, J.P.; Zhou, Z.W.; Zhou, S.F. Human CYP2C8: Structure, substrate specificity, inhibitor selectivity, inducers and polymorphisms. Curr. Drug. Metab. 2009, 10, 1009-1047.

56. Pang, C.Y.; Mak, J.W.; Ismail, R.; Ong, C.E. In vitro modulatory effects of flavonoids on human cytochrome P450 2C8 (CYP2C8). Naunyn Schmiedebergs Arch. Pharmacol. 2012, 385, 495-502.

57. Walsky, R.L.; Obach, R.S.; Gaman, E.A.; Gleeson, J.P.; Proctor, W.R. Selective inhibition of human cytochrome P4502C8 by montelukast. Drug Metab. Dispos. 2005, 33, 413-418.

58. Ogilvie, B.W.; Zhang, D.; Li, W.; Rodrigues, A.D.; Gipson, A.E.; Holsapple, J.; Toren, P.; Parkinson, A. Glucuronidation converts gemfibrozil to a potent, metabolism-dependent inhibitor of CYP2C8: Implications for drug-drug interactions. Drug Metab. Dispos. 2006, 34, 191-197.

Sample Availability: Not Available.

(C) 2013 by the authors; licensee MDPI, Basel, Switzerland. This article is an open access article distributed under the terms and conditions of the Creative Commons Attribution license (http://creativecommons.org/licenses/by/3.0/). 